\title{
INFORMATICS TOOLS USING ESTIMATION DURING PILOT TRAINING
}

\author{
J. Gruszecki, Z. Zajdel,P. Rzucidło
}

Rzeszow University of Technology, Department of Avionics and Control, ul. W. Pola 2, 35-959 Rzeszow, Poland. E-mail: awionjgr@prz.edu.pl,pawelrz@prz.edu.pl Received 08 May 2007, accepted 10 Oct 2007
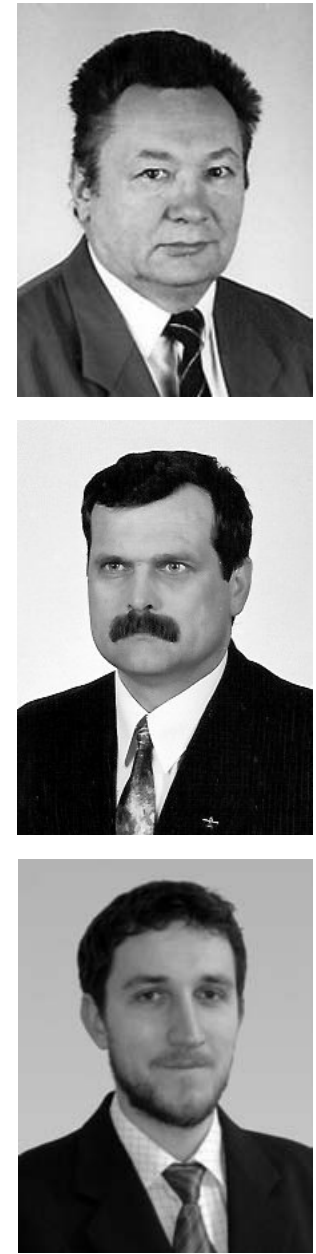

\section{Jan GRUSZECKI, Prof Dr Sc Eng}

Date of birth: 1941.

Affiliations and functions: Head of the Department of Avionics and Control at the Faculty of Mechanical Engineering and Aeronautics of Rzeszow University of Technology.

Research interests: The rough set theory, the decision to undertake helping methods, the control system projects at informatics formulation and design.

Experience: Member of the programme working groups of the JEP-12095-97 (as part of the structure requirements and of Syllabuses and Course Study Programmes for avionics specialization consistent with the JAR 66 cat C Aircraft Control Systems) and the ARTs - Leonardo Programme (multimedia lectures for pilots and aviation mechanics).

\section{Zbigniew ZAJDEL, PhD Eng}

Date of birth: 1956.

Affiliations and functions: Lecturer at the Department of Avionics and Control from 2001 to 2007, an ex-airline pilot, a pilot instructor, and from May 1993 to November 2000 the managing director of the Aviation Training Centre of the Rzeszow University of Technology.

Research interests: Air navigation, flight safety, commercial flight performances, and new methodologies for aviation training and design are the educational and research activities.

Experience: A member of programme working groups of the JEP-12095-97 (structure, requirements, and syllabuses and course study programmes for avionics specialization consistent with JAR 66 cat C - Aviation Legislation) and the ARTs - Leonardo Programme (multimedia lectures for pilots and aviation mechanics).

\section{Pawel RZUCIDŁO, PhD Eng}

Education: M.Sc. (Eng.) degree in Aeronautics, Rzeszow University of Technology, Faculty of Mechanical Engineering and Aeronautics. 2001 to 2005: PhD studies; Rzeszow University of Technology, Faculty of Mechanical Engineering and Aeronautics; specialization: Machine Building and Exploitation.

Affiliations and functions: 2005 to present: researcher, Rzeszow University of Technology, Department of Avionics and Control.

Research interest: aircraft control with an emphasis on interactions between human and machine.

Publications: author of book and ten scientific articles, co-author of over 20 conference papers.

\begin{abstract}
The human interest in flight simulators and tools that facilitate the effective formation of piloting skills has more than half a century of tradition. Marked growth development of these tools happened after the implementation of digital techniques into the structure of simulators and after the obtainment of independent computer applications the enabling the operator's predispositions and performance level to be controlled and estimated. The questions that are posed in this area of such specific tools have been very often oriented towards the possibility and reasonableness of replacing real training flights with a simulation technique.

Working on the problem of improving the level of safety in civil aviation, the authors conducted tests to determine the possibility of formalizing the principles of admittance for computers tools that are identified as OTD (Other Training Device) followed from JAR STD 3A.005 (f) regulations. One of the aims of the experiments was to confirm the usefulness of the statistical methods that had been used to identify the pilot's skill level estimated for short series of flights. RUT Aviation Training Centre students, whose individual predispositions as operators and performance levels had been estimated using the WOMBAT - CS TOOL, took part in experiments based on elements of flight normalized in JAR - FCL 1.210. In this paper, the authors present and discuss the assumptions, accomplishments, and results of that experiment.
\end{abstract}

Keywords: pilot training, operator selection, evaluation method, safety. 


\section{Introduction}

Considering the particular requirements for pilot and aircraft, we should take the complete man-machine system into account. Requirements for operator and flying object should not be separated, because a flying object is built for the purposes of a human operator. On the other hand, man is trained to reach best performance of complete pilot-aircraft system. Passing over particular characteristics of flying object we can ask: "Is it possible to shape operator skills for purposes of flying object? How to evaluate piloting technique during training process?".

The answers to these questions will be possible after characterizing the following notions: the skills of the operator when performing simple activities (reflexes, habits), the possibility to utilize facts (experience), and skills interconnected with knowledge (inference). Considering the pilot-operator system as a structure that is able to realise the three groups of operations mentioned above, we can formulate the requirements for the control of a flying object. These requirements exist as legal regulations, rules, and procedures for teaching and training pilots. They are also concerned with monitoring knowledge and skills.

Talking about the scope of a pilot's knowledge, we mean the theoretical and experimental aspects of aircraft control and its interactions with the surroundings. The pilot/operator should be acquainted with the principles of the properties of flying objects (including all subassemblies), atmospheric phenomena, and rules of control. This knowledge should allow the pilot to communicate and operate in every place on the Earth, to realise all necessary ground operations (refuelling, ordering repairs, and supporting passengers) and even to know the habits of different communities. The use of the appropriate knowledge in a specific situation can be defined as the ability to infer. The skill for connecting pieces of knowledge with facts allows a pilot to optimise low level activities (create reflex actions).

We can define experience as the ability to perform a specified activity in a fixed time. Such a definition of experience is identified with the acquisition of remembered facts. This aptitude is renewable and modifiable depending on the method of collecting facts. This process can proceed during:

- flight under various conditions,

- training on a real object,

- training on simulator,

- $\quad$ aircraft exploitation learning process.

The evaluation of operator experience can be measurable, and miscellaneous measures (range, quality of approximation, fuzzy range, and classification) can be applied to determine which skills have been acquired.

The most numerous group of operations are lowlevel training activities. The completion of such tasks is strictly connected with simple physical actions. These actions are restricted by defined thresholds of precision.

Three areas of pilot's know-how (presented as a hierarchical structure in Fig 1) are tested during the training and education of pilots. In this article, the authors concentrate on methods of evaluating the improvement of a pilot's skills. The AL200MCC simulator and WOMBAT situational awareness and stress tolerance testing system have been used for these purposes.

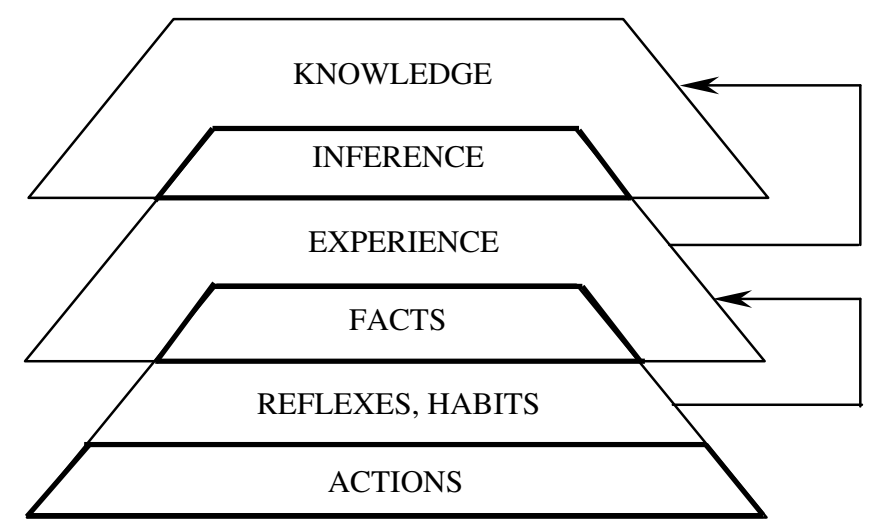

Fig 1. Areas of pilot's know-how

\section{Method of training evaluation}

Every action of a pilot should be evaluated in the context of the legal regulations that define methods for monitoring the maintenance of flight parameters. The JAR - AWO regulation (JAR - All Weather Operations) allows applying statistical methods to the assessment of a pilot's skill [2]. This method is based on the Rayleigh distribution. Appropriate and allowable deviations of particular flight parameters and levels of training are specified in JAR - FCL 1.210 (JAR - Flight Crew Licensing) regulations [3].

The method that is presented to evaluate training is based on a table of statistical values (table 1). Deviations of chosen variables are assigned statistical values (range from 0 to 2) and associated with a specified flight task. The assignment of deviations is done with the use of templates preparing for every kind of task. An example of a template for a "rate one" task, intercepting and 
maintaining the desired heading HDG 100 , is presented in figure 2. Making use of templates, a table of statistical values, and maximal deviations of flight parameters enable success curves to be drawn (Fig 3). The success curve illustrates the sum of the deviations recorded during training according to the number of samples.

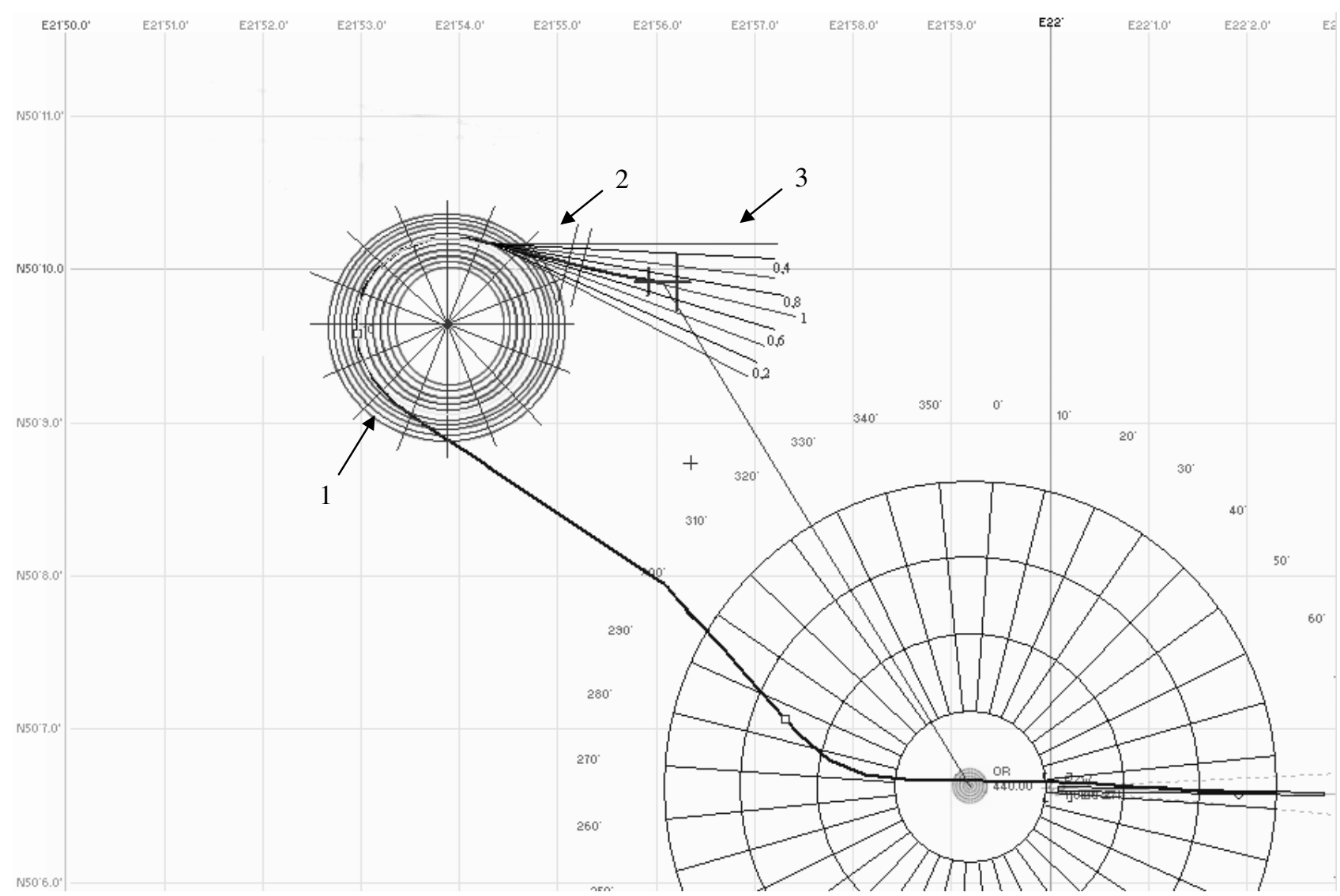

Fig 2. Template of deviations:

1. Constant bank angle "rate one".

2. Interception of desired heading (HDG 100).

3. Precision of maintaining constant heading (HDG 100)

Table 1. Assignment of statistical values

\begin{tabular}{|c|c|c|c|c|c|c|c|}
\hline \multicolumn{7}{|c|}{ Acceptable tolerances } & \multirow{2}{*}{ heading } \\
\hline \hline & $\begin{array}{c}\text { radio } \\
\text { navigation } \\
\text { tracking) }\end{array}$ & altitude & $\begin{array}{c}\text { climb } \\
\text { gradient }\end{array}$ & $\begin{array}{c}\text { turns radius } \\
\text { "RATE } \\
\text { ONE" }\end{array}$ & $\begin{array}{c}\text { flight time } \\
\text { after passing } \\
\text { beacon }\end{array}$ & $\begin{array}{c}\text { precision of } \\
\text { QDM, QDR } \\
\text { interception }\end{array}$ & Deviation \\
\cline { 1 - 6 }$[\mathrm{deg}]$ & {$[\mathrm{deg}]$} & {$[\mathrm{feet}]$} & {$[$ feet] } & {$[\mathrm{NM}]$} & {$[\mathrm{sec}]$} & {$[\mathrm{NM}]$} & \\
\hline $1-2.5$ & $1-2.5$ & $0-50$ & $0-50$ & $0-0.1$ & $0-3$ & $0-0.1$ & 0.2 \\
\hline $2.5-5$ & $2.5-5$ & $50-100$ & $50-100$ & $0.1-0.2$ & $3-6$ & $0.1-0.2$ & 0.4 \\
\hline $5-7.5$ & $5-7.5$ & $100-150$ & $100-150$ & $0.2-0.3$ & $6-9$ & $0.2-0.3$ & 0.6 \\
\hline $7.5-10$ & $7.5-10$ & $150-200$ & $150-200$ & $0.3-0.4$ & $9-12$ & $0.3-0.4$ & 0.8 \\
\hline $10-12.5$ & $10-12.5$ & $200-250$ & $200-250$ & $0.4-0.5$ & $12-15$ & $0.4-0.5$ & 1.0 \\
\hline $12.5-15$ & $12.5-15$ & $250-300$ & $250-300$ & $0.5-0.6$ & $15-18$ & $0.5-0.6$ & 1.2 \\
\hline $15-17.5$ & $15-17.5$ & $300-350$ & $300-350$ & $0.6-0.7$ & $18-21$ & $0.6-0.7$ & 1.4 \\
\hline $17.5-20$ & $17.5-20$ & $350-400$ & $350-400$ & $0.7-1$ & $21-24$ & $0.7-1$ & 1.6 \\
\hline$>20$ & $>20$ & $>400$ & $>400$ & $>1$ & $>24$ & $>1$ & 2.0 \\
\hline
\end{tabular}




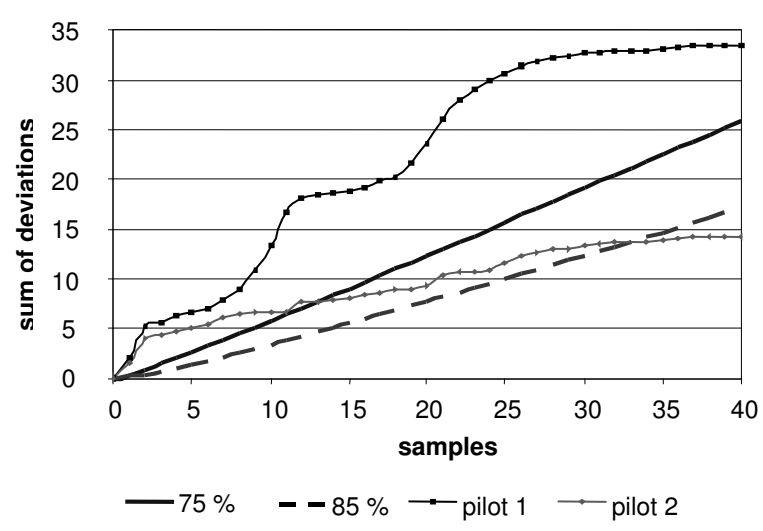

Fig 3. Example of curves of success

The graph presented in figure 3 is plotted with the assumption that maximal deviations conform to the Rayleigh distribution. The probability density in this distribution can be expressed as:

$$
p(x)=\frac{x^{2}}{\lambda_{0}^{2}} e^{-\frac{1}{2}\left(\frac{x}{\lambda_{0}}\right)^{2}}
$$

where: $\quad \lambda_{0}$ - parameter of Rayleigh distribution, $\mathrm{x}$ - maximal deviation.

The probability of a maximal deviation smaller than $\mathrm{x}_{0}$ is:

$$
P\left(x_{0}\right)=\int_{0}^{x_{0}} p(x) d x=1-e^{-\frac{1}{2}\left(\frac{x}{\lambda_{0}}\right)^{2}}
$$

where:

$$
\lambda_{0}^{2}=\frac{1}{2} \int_{0}^{x_{0}} x^{2} p(x) d x
$$

Equation (3) can be approximated with sufficient precision by this formula:

$$
\lambda_{0}^{2}=\frac{1}{2 \mathrm{n}} \sum_{\mathrm{i}=1}^{\mathrm{n}}\left(\mathrm{x}_{\mathrm{i}}\right)^{2}
$$

where $\mathrm{n}-$ number of samples, $\mathrm{x}_{\mathrm{i}}-$ maximal deviation in every sample.

The large number of samples permits the estimation of $\lambda_{0}^{2}$ directly from dependences (1-4). The use of an extra parameter, $\mu$ (characterized by normal distribution with zero expected value and standard deviation equal to $1)$, is obligatory for the estimation of $\lambda$ when there are not many samples:

$$
\mu=\frac{\left(\lambda^{2}-\lambda_{0}^{2}\right) \sqrt{\mathrm{n}}}{\lambda_{0}^{2}}
$$

Defining parameter $\tau$ for the established trust factor, we obtain:

$$
\tau=\frac{1}{\sqrt{2 \pi}} \int_{-\infty}^{\mu} e^{-\frac{\mu^{2}}{2}} d \mu
$$

For $\mathrm{P}\left(\mu>-\mu_{1}\right)=\mathrm{P}\left(\mu<\mu_{1}\right)$ we get only one value of trust factor $\mu$. It can be concluded that the statistical method presented checks whether the recorded deviation is located in assumed norms with a sufficient level of trust. The method is satisfactory even when the number of samples is not large.

We can draw a theoretical curve of success using formulas (1) to (6). Assuming the probability of the correct realization of operation $\mathrm{P}\left(\mathrm{x}_{0}\right)$, we can obtain the curve of success for $\lambda_{0}$ from dependence (1)

$$
\frac{\mathrm{x}_{0}}{\lambda_{0}}=\sqrt{-2 \ln \left(1-\mathrm{P}\left(\mathrm{x}_{0}\right)\right)}
$$

We can notice in figure 3 that the curve of success can intersect the curve of deviations (pilot 2 and thrust factor $85 \%$ ) but does not necessarily have to (pilot 1). Results achieved by pilot 1 are better than assumed whereas results of the test of the second operator are below expected.

\section{FNPT II MCC simulator, results of experiment}

A group of 18 students took part in an experiment realised with the use of a AL200 MCC flight simulator. Graduates of flight school before the IFR course and those with other levels of aviation experience had been selected. The main objective of the experiment was to demonstrate the usability of simulation software for obtaining ability for IFR flights.

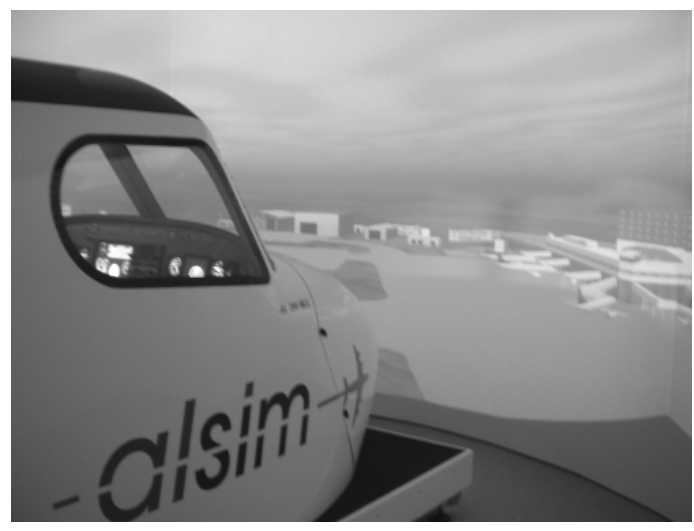

Fig 4. AL200 MCC flight simulator at RUT Training Centre 
Considering the wide variety of subjects of IFR flights, training was limited to standard procedures connected with NDB (non directional radio beacon). A theoretical IFR course preceded training on the simulator. A series of lectures was divided into two parts: scanning of indicators (part I) and methods of intercepting QDM (Magnetic Bearing to the Station) and QDR (Reciprocal Magnetic Bearing, the opposite of QDM) (part II). A group of eight students was selected for the next part of the experiment after the theoretical course, WOMBAT test, and preliminary training on the simulator (Tab 2). The four students with the best results on WOMBAT and a large amount of flying time were selected as group B. The four students with the worst results on WOMBAT were assigned to group A. The group A training program was extended by extra hours on the PC flight simulator Flight Pro v 6.2.0.

Table 2. Qualification results of students

\begin{tabular}{|c|c|c|c|c|c|c|c|}
\hline Number & \multicolumn{2}{|c|}{ Pilot/operator } & License & $\begin{array}{c}\text { Total flying } \\
\text { time }[\mathrm{h}]\end{array}$ & $\begin{array}{c}\text { Commander } \\
\text { flying time }[\mathrm{h}]\end{array}$ & $\begin{array}{c}\text { WOMBAT } \\
\text { (test) }\end{array}$ & $\begin{array}{c}\text { Navigation } \\
\text { (test) }\end{array}$ \\
\hline 1. & Student 1 & & GL/AL & 390 & 240 & 237.0 & 21 \\
\hline 2. & Student 2 & & AL & 51 & 13 & 217.8 & 19 \\
\hline 3. & Student 3 & B1 & G & 3 & 1 & 371.2 & 12 \\
\hline 4. & Student 4 & B3 & GL & 140 & 108 & 320.1 & 23 \\
\hline 5. & Student 5 & A2 & GL/AL & 270 & 220 & 206.1 & 23 \\
\hline 6. & Student 6 & B4 & GL/AL & 70 & 20 & 314.3 & 24 \\
\hline 7. & Student 7 & & GL/AL & 220 & 160 & 291.7 & 19 \\
\hline 8. & Student 8 & & G & 35 & 5 & 318.0 & 21 \\
\hline 9. & Student 9 & & GL & 120 & 75 & 192.7 & 23 \\
\hline 10. & Student 10 & & GL/AL & 120 & 70 & 280.4 & 20 \\
\hline 11. & Student 11 & A3 & GL & 100 & 65 & 257.2 & 21 \\
\hline 12. & Student 12 & B2 & GL & 350 & 320 & 338.9 & 21 \\
\hline 13. & Student 13 & A1 & GL & 95 & 65 & 204.2 & 24 \\
\hline 14. & Student 14 & & AL & 51 & 12 & 316.7 & 14 \\
\hline 15. & Student 15 & A4 & G & 40 & 0 & 256.5 & 20 \\
\hline 16. & Student 16 & & AL & 33 & 4 & 318.8 & 14 \\
\hline 17. & Student 17 & & AL & 72 & 24 & 273.4 & 19 \\
\hline 18. & Student 18 & & GL & 60 & 40 & 270.9 & 18 \\
\hline
\end{tabular}

$\mathrm{AL}$ - aircraft license, GL - glider license, $\mathrm{G}$ - glider experience, no license

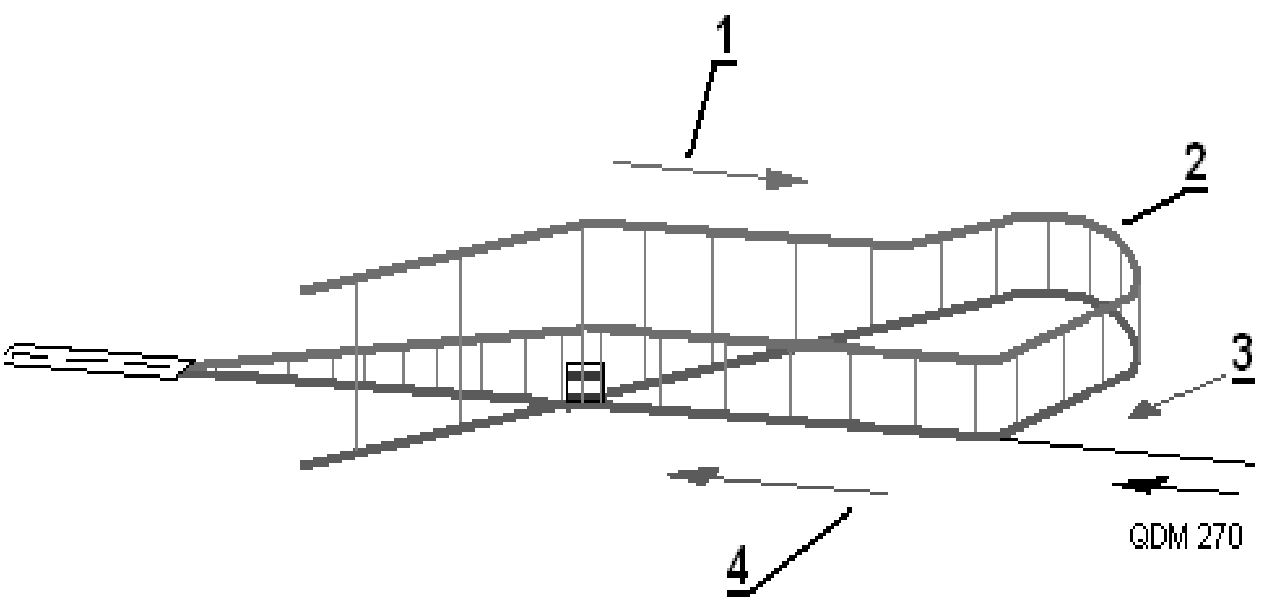

Fig 5. Example of piloting task:

1. Descending to $2000 \mathrm{ft}$ after passing NDB RZ.

2. Flight three minutes outbound RZ.

3. Interception of QDM $270 \mathrm{RZ}$ after three minutes.

4. Maintaining heading of $270^{\circ}$ and descending after passing NDB to landing 
Table 3. Results of an exemplary task

\begin{tabular}{|c|c|c|c|c|c|c|c|}
\hline Sample & Deviation & $\mathrm{X}_{\mathrm{i}}$ & $\sum \mathrm{x}_{\mathrm{i}}^{2}$ & Sample & Deviation & $\mathrm{X}_{\mathrm{i}}$ & $\sum \mathrm{x}_{\mathrm{i}}^{2}$ \\
\hline 1 & 0.00 & 1.00 & 1.00 & 21 & 0.00 & 0.80 & 18.24 \\
\hline 2 & 0.20 & 0.80 & 1.64 & 22 & 0.00 & 1.00 & 19.24 \\
\hline 3 & 0.40 & 0.60 & 2.00 & 23 & 0.60 & 0.40 & 19.40 \\
\hline 4 & 0.60 & 0.40 & 2.16 & 24 & 0.60 & 0.40 & 19.56 \\
\hline 5 & 0.40 & 0.60 & 2.52 & 25 & 0.80 & 0.20 & 19.60 \\
\hline 6 & 0.40 & 0.60 & 2.88 & 26 & 0.20 & 0.80 & 20.24 \\
\hline 7 & 0.00 & 1.00 & 3.88 & 27 & 0.40 & 0.60 & 20.60 \\
\hline 8 & 0.40 & 0.60 & 4.24 & 28 & 0.40 & 0.60 & 20.96 \\
\hline 9 & 0.00 & 1.40 & 6.20 & 29 & 0.60 & 0.40 & 21.12 \\
\hline 10 & 0.00 & 1.40 & 8.16 & 30 & 0.40 & 0.60 & 21.48 \\
\hline 11 & 0.00 & 1.60 & 10.72 & 31 & 0.60 & 0.40 & 21.64 \\
\hline 12 & 0.00 & 1.20 & 12.16 & 32 & 0.80 & 0.20 & 21.68 \\
\hline 13 & 0.40 & 0.60 & 12.52 & 33 & 0.80 & 0.20 & 21.72 \\
\hline 14 & 0.60 & 0.40 & 12.68 & 34 & 0.80 & 0.20 & 21.76 \\
\hline 15 & 0.60 & 0.40 & 12.84 & 35 & 0.6 & 0.40 & 21.92 \\
\hline 16 & 0.40 & 0.60 & 13.20 & 36 & 0.6 & 0.40 & 22.08 \\
\hline 17 & 0.20 & 0.80 & 13.84 & 37 & 0.8 & 0.20 & 22.12 \\
\hline 18 & 0.40 & 0.60 & 14.20 & 38 & 0.6 & 0.40 & 22.28 \\
\hline 19 & 0.00 & 1.20 & 15.64 & 39 & 0.8 & 0.20 & 22.32 \\
\hline 20 & 0.00 & 1.40 & 17.60 & 40 & 1 & 0.00 & 22.32 \\
\hline
\end{tabular}

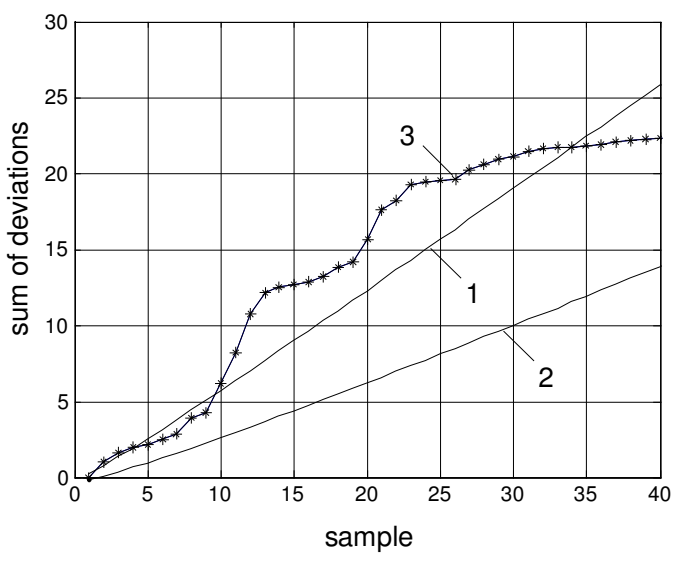

Fig 6. Graph of success based on results presented in table 3:

1 - assumed curve of success: $\mathrm{P}\left(\mathrm{x}_{0}\right)=75 \%, \mathrm{x}_{0}=1$,

2 - assumed curve of success: $\mathrm{P}\left(\mathrm{x}_{0}\right)=90 \%, \mathrm{x}_{0}=1$,

3 - results obtained during test

Simulated flights included elementary elements of radio navigation. The performance of particular tasks, precision of manoeuvres, and maintenance of particular flights parameters were evaluated. An example of a piloting task performed during simulated flight is presented in figure 5. Reference data was obtained during simulated flight realized with the use of autopilot on an AL200MCC simulator. The method used to draw the success curve follows:

description of tasks assigned for realisation on simulator,

- performance of simulated flights while parameters are recorded,

- $\quad$ assumption of maximal deviations $\mathrm{x}_{0}$ (Tab 1),

- assumption of trust level $\tau$ for probability of maximal deviation $\mathrm{P}\left(\mathrm{x}_{0}\right)$,

- calculation of $\lambda_{0}$,

- definition of deviation of analyzed flight parameters and drawing of success curve (as sum of deviations in function of number of samples).
A set of results of an exemplary task is presented in table 3 . The curve of success plotted for the participant in this experiment is presented in figure 6.

Analysing the curve of success, we can see that the operator achieved an adequate level of performance after 34 samples (assuming probability $\mathrm{P}\left(\mathrm{x}_{0}\right)=75 \mathrm{v} \%$ ). The intersection of curve 1 and 3 in 34 samples and next the slow increment of 3 indicates that the training process has been successfully completed. With the assumption that probability $\mathrm{P}\left(\mathrm{x}_{0}\right)=90 \%$, there was no transition from the learning process to certain control of the aircraft.

A comprehensive record of the experiments performed has been presented in work [1]. This work is available at the Department of Avionics and Control of the Faculty of Mechanical Engineering and Aeronautics of the Rzeszow University of Technology.

\section{WOMBAT test}

As presented in chapter 3, the selection process of pilots/operators was based on the WOMBAT system [5]. This system is a very important informatics tool that permits the objective verification of a pilot's skills, a pilot's predisposition for fast and adequate adaptation, and a pilot's ability to make faultless inferences. The WOMBAT situational awareness and stress tolerance test is a modern psychological assessment tool for selecting complex system operators such as pilots and air traffic controllers [5].

Operator performance depends largely on situational awareness. An operator of a complex system must search for, evaluate, and integrate information about all relevant events, conditions, and resources; quickly assess changes in situational priorities; and allocate attention accordingly. To determine an individual's aptitude to meet these demands requires a complex test in which high scores depend on $[5,6]$ :

- finding out what is important now and in the long run and allocating priorities accordingly, 
- perceiving a situation correctly by avoiding preconceived assumptions and subjective biases and being vigilant,

- discovering rules that are not explicit through induction and deduction,

- recognizing serendipitous opportunities quickly and seizing them before they pass,

- ignoring irrelevant distractions and tolerating frustration when things are going badly,

- coping with the stress of high workload periods and poor performance indicators,

- coping with the boredom of routine tasks and resisting complacency during periods of low workload.

Just before the test, candidates go through a succession of instruction pages and accompanying exercises. The default time limit for the instruction period is 60 minutes. The individual tasks involve keeping track of multiple moving targets, spatial orientation, pattern recognition, and short-term (working) memory. Particular activities and results are visualized as graphics or digital data. During the test, the operator reaches an asymptotic performance level after a short practice period. The WOMBAT test runs during nine consecutive scoring intervals of 10 minutes each for a total of 90 minutes. Moving from one interval to the next is totally transparent and goes unnoticed by the candidate.

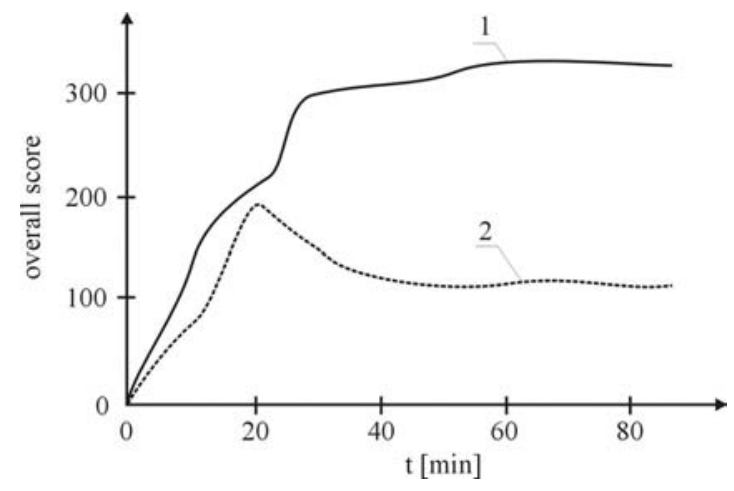

Fig 7. Comparison of two WOMBAT tests results: successful (1) and unfavourable (2)

The overall score is the sum of the total bonus score, tracking score, and collision detection score. Changes in the predicted final score obtained during successful (1) and unfavourable (2) tests are presented in figure 7. Curve 1 indicates that the operator has predispositions for learning, ignoring stress and failures, and making proper inferences and using correct rules. The opposite properties and insufficient predispositions of an operator are indicated in curve 2 .

Extended data and the results of experiments obtained with the use of the WOMBAT system will be presented in the future, after finishing some additional research processes.

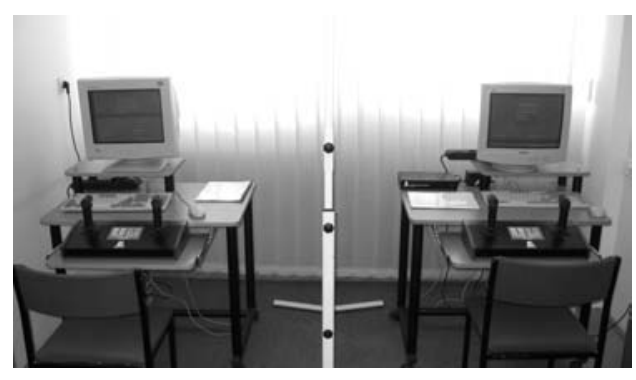

Fig 8. General view of laboratory for predicting human performance; RUT, Department of Avionics and Control

\section{Conclusions}

The subject presented in this work is a part of the authors' activities connected to the improvement of pilot training methods and increase in flight safety. We suppose the statistical method presented will be very helpful for monitoring the predispositions of pilots during training and professional activity, and the introduction of situational awareness and the stress tolerance test leads to more objective selection of candidates for the pilot training programme of the aeronautics and aerospace branch of study at Rzeszow University of Technology. The authors conclude that the informatics tools presented allow two important questions to be answered:

- $\quad$ should a candidate be trained as a pilot?

- should the qualifications of pilots be improved?

It seems that the two simple informatics tools presented are objective and useful for the purposes described. There is a possibility to build more complex and very expensive tools to assess operator skills and abilities, for example hi-tech flight simulators integrated with extended human factor performance systems. Unfortunately, the integration and implementation of such devices for the selection process of pilot candidates require a considerable amount of money and time.

\section{References}

1. HERMAN, R., KAZMIERSKI, M. Application of PC flight simulators for preliminary training of pilots. MSc Thesis. Faculty of Mechanical Engineering and Aeronautics, Rzeszow University of Technology. Rzeszow, 2007. In Polish.

2. Joint Aviation Requirements - all weather operations. In Joint Aviation Authorities, GILC, Warszawa 1996.

3. Joint Aviation Requirements - flight cress licensing. In Joint Aviation Authorities, GILC, Warszawa, 2002.

4. ROSCOE, SN., CORL, L., LAROCHE, J. Predicting human performance. Helio Press Inc., Canada, 2001.

5. WOMBAT CS - manuel du candidat. Corpyright Aéro Innovation Inc. CP 87 Perrefouds, QC H9H. 4K8 Canada, 1991-1994.

6. WOMBAT Modern Psychological Assessment. In http://www.aero.ca, Aero Innovation, 1998. 